\title{
The Function of the
} Hypothalamic-Pituitary-Adrenal Axis During Experimental Autoimmune Encephalomyelitis: Involvement of Oxidative Stress Mediators

\author{
Svetlana Trifunovic ${ }^{1}$, Ivana Stevanovic ${ }^{2}$, Ana Milosevic ${ }^{1}$, Natasa Ristic ${ }^{1}$, Marija Janjic ${ }^{1}$, \\ Ivana Bjelobaba ${ }^{1}$, Danijela Savic', Iva Bozic ${ }^{1}$, Marija Jakovljevic ${ }^{1}$, Katarina Tesovic ${ }^{1}$, \\ Danijela Laketa ${ }^{3}$ and Irena Lavrnja ${ }^{1 *}$ \\ 1 Institute for Biological Research "Siniša Stanković"-National Institute of Republic of Serbia, University of Belgrade, Belgrade, \\ Serbia, ${ }^{2}$ Medical Faculty of Military Medical Academy, Institute of Medical Research Belgrade, University of Defense, \\ Belgrade, Serbia, ${ }^{3}$ Department for General Physiology and Biophysics, Faculty of Biology, University of Belgrade, Belgrade, \\ Serbia
}

OPEN ACCESS

Edited by:

Neil James MacLusky, University of Guelph, Canada

Reviewed by:

Richard G. Hunter, University of Massachusetts Boston,

United States

Taka-aki Koshimizu, Jichi Medical University, Japan

*Correspondence: Irena Lavrnja irenam@ibiss.bg.ac.rs orcid.org/0000-0002-0607-5594

Specialty section:

This article was submitted to Neuroendocrine Science, a section of the journal Frontiers in Neuroscience

Received: 04 January 2021 Accepted: 29 April 2021

Published: 17 June 2021

Citation:

Trifunovic S, Stevanovic I, Milosevic A, Ristic N, Janjic M,

Bjelobaba I, Savic D, Bozic I, Jakovljevic M, Tesovic K, Laketa D and Lavrnja I (2021) The Function of the Hypothalamic-Pituitary-Adrenal Axis During Experimental Autoimmune Encephalomyelitis: Involvement of Oxidative Stress Mediators.

Front. Neurosci. 15:649485. doi: 10.3389/fnins.2021.649485
Multiple sclerosis (MS) is an inflammatory, demyelinating disease with an unknown origin. Previous studies showed the involvement of the hypothalamic-pituitary-adrenal (HPA) axis to susceptibility to autoimmune diseases, including MS, and its best-characterized animal model, experimental autoimmune encephalomyelitis (EAE). During MS/EAE, innate immune cells are activated and release cytokines and other inflammatory mediators, leading to a vicious cycle of inflammation. In response to inflammation, the activated HPA axis modulates immune responses via glucocorticoid activity. Because the mechanisms involving oxidative stress to the HPA axis are relatively unrevealed, in this study, we investigate the inflammatory and oxidative stress status of HPA axis during EAE. Our results reveal an upregulation of Pomc gene expression, followed by POMC and ACTH protein increase at the peak of the EAE in the pituitary. Also, prostaglandins are well-known contributors of HPA axis activation, which increases during EAE at the periphery. The upregulated Tnf expression in the pituitary during the peak of EAE occurred. This leads to the activation of oxidative pathways, followed by upregulation of inducible NO synthase expression. The reactive oxidant/nitrosative species (ROS/RNS), such as superoxide anion and NO, increase their levels at the onset and peak of the disease in the pituitary and adrenal glands, returning to control levels at the end of EAE. The corticotrophs in the pituitary increased in number and volume at the peak of EAE that coincides with high lipid peroxidation levels. The expression of MC2R in the adrenal glands increases at the peak of EAE, where strong induction of superoxide anion and malondialdehyde (MDA), reduced total glutathione $(\mathrm{GSH})$ content, and catalase activity occurred at the peak and end of EAE compared with controls. The results obtained from this study may help in understanding the mechanisms and possible pharmacological modulation in MS and demonstrate an effect of oxidative stress exposure in the HPA activation during the course of EAE.

Keywords: multiple sclerosis, experimental autoimmune encephalomyelitis, hypothalamic-pituitary-adrenal axis, oxidative stress, cytokines 


\section{INTRODUCTION}

Multiple sclerosis (MS) is an idiopathic disease, with an origin that remains elusive. The causes that contribute to MS involve immune, genetic/epigenetic, and environmental factors. It is proposed that the autoimmune component underlies the onset of MS, with neuroinflammatory and neurodegenerative outcomes. Although it does not replicate every sequence of MS, experimental autoimmune encephalomyelitis (EAE) is the bestdescribed animal model of MS and shares some features with the disease, mainly at histopathological and immunological levels. The initial period of EAE is characterized by the breakdown of the blood-brain barrier, followed by inflammatory cell infiltration in the white matter of the CNS. At the later stages, inflammation is accompanied by microglia and astrocyte activation, with ensuing demyelination and axonal loss (Bjelobaba et al., 2017, 2018).

Besides well-known immune-mediated demyelinating effects during MS, several studies pointed to and linked the endocrine system to the predisposition and severity of the disease (Huitinga et al., 2003; Gold et al., 2005; Melief et al., 2013). The endocrine system interacts with the nervous and immune system and elicits a response to homeostasis disturbance provoked by inflammation, stress, and/or infection (Smith and Vale, 2006; Procaccini et al., 2014). In this context, the critical player in maintaining physiological homeostasis under these circumstances is the hypothalamic-pituitary-adrenal (HPA) axis. Basically, parvocellular neurons in the paraventricular nucleus of the hypothalamus secrete corticotropin-releasing hormone (CRH) at the median eminence. $\mathrm{CRH}$ is transported through the hypothalamic-hypophysial portal blood vessels to the anterior pituitary, where it stimulates the release of adrenocorticotropic hormone (ACTH) from corticotrophs (Dallman et al., 1987) to the systemic circulation (Smith and Vale, 2006; Herman and Tasker, 2016). At the level of adrenal glands, ACTH acts via melanocortin 2 receptor (MC2R) causing synthesis and secretion of the glucocorticoids (GCs) (Beuschlein et al., 2001) cortisol (dominant GC in humans) and corticosterone (dominant GC in rodents) into the bloodstream (Smith and Vale, 2006). GCs' action in the target tissues depends on the expression of glucocorticoid and mineralocorticoid receptors and on the cellular metabolism of GCs mediated by $11 \beta$-hydroxysteroid dehydrogenase isozymes (Chapman et al., 2013). In the tissues, especially in the placenta or kidney, the biologically active forms of glucocorticoids-cortisol and corticosterone-are converted to the inactive forms, cortisone and 11-dehydrocorticosterone, respectively, by the action of $11 \beta$-hydroxysteroid dehydrogenase 2 . On the other hand, another isozyme, $11 \beta$-hydroxysteroid dehydrogenase 1, expressed especially in the liver, brain, inflammatory cells, adipose tissue, and gonads, regenerates active forms of GCs (Chapman et al., 2013; Prevatto et al., 2017). The release of GCs from the adrenal glands in return suppresses the release of ACTH levels in the anterior pituitary and CRH levels in the hypothalamus, representing a typical homeostatic negative feedback control mechanism (George et al., 2006).
Previous studies linked the dysregulation of the HPA axis and susceptibility to autoimmune diseases. Specifically, it was proposed that modulation of HPA axis activity is associated with the predisposition, severity, and heterogeneity of MS (Grasser et al., 1996; Gold et al., 2005; Melief et al., 2013). During MS/EAE, innate immune cells are activated and cytokines and other inflammatory mediators, including prostaglandins that are well-known contributors of HPA activation, are released (Silverman et al., 2005; Bellavance and Rivest, 2014). In response to inflammation, the activated HPA axis modulates immune responses via the activity of GCs. Pertinent to this, during inflammatory processes, HPA activation represents an important protective mechanism, where GCs, the end products of the HPA axis, exhibit immunosuppressive effects on the inflammatory setup in MS/EAE. Therefore, cortisol is used as first-line therapy in treating MS relapses (Bjelobaba et al., 2017). However, excessive HPA stimulation and long-term therapy increase susceptibility to infection and have well-known effects on neuroinflammation and cognition, thus limiting the therapeutic use of GCs in MS (Goodin, 2014; dos Santos et al., 2019). Subsequent to increased inflammation in MS, excessive generation of reactive oxygen species (ROS) (Berg et al., 2004) due to deregulation of mitochondrial electrontransport chain activity, induced by inflammatory mediators, may provoke oxidative damage to a variety of cells (Miljković and Spasojević, 2013). Besides the increased generation of ROS, depletion of antioxidants additionally contributes to redox imbalance, leading to oxidative stress (Birben et al., 2012). While physiological levels of ROS have a fundamental role in maintaining the homeostasis of the HPA axis (Spiers et al., 2015; Prevatto et al., 2017), increased generation of ROS, in an inflammatory setup, induces hyperactivation in the HPA axis. In addition, ROS modulates the redox regulation of various intracellular signaling systems and enhances the susceptibility of various tissues to injury (Mittal et al., 2014; Brown and Griendling, 2015). The exact mechanisms linking oxidative stress to the HPA axis are relatively unidentified (Schiavone et al., 2013).

Therefore, the aim of this study was to investigate the inflammatory and redox status of the HPA axis during EAE, because a better understanding of the relations between the neuroendocrine and the immune system may yield potent paradigms for the treatment of autoimmune diseases, including MS.

\section{MATERIALS AND METHODS}

\section{Experimental Animals}

In this study, we used 2-month-old female rats of Dark Agouti (DA) (RRID:RGD_21409748) strain from the local colony. Experimental procedures and animal care were performed in accordance with European Ethical Normative (Directive 2010/63/EU) on the protection of animals used for experimental and other scientific purposes and in accordance with national regulative given by the Animal Welfare Law of the Republic of 
Serbia ("Official Gazette of Republic of Serbia" No. 41/2009). The experimental protocols were approved by The Ministry of Agriculture, Forestry and Water Economy of the Republic of Serbia (permit no. 323-07-05970/2020-05). The reported results comply with the ARRIVE guidelines. The animals were kept under standard laboratory conditions, with $12 \mathrm{~h}$ dark/light cycle, at constant temperature $\left(23 \pm 2^{\circ} \mathrm{C}\right)$ and humidity $(50-$ $60 \%$ ), where they had free access to laboratory chow and water ad libitum. In total, 72 animals were used for the experiments. The number of animals for EAE experiments was calculated using power calculations ( $G^{*}$ Power Freeware, Version 3.1.9.7). Based on an alpha error probability of $<0.05$, a beta of $<0.95$, and standard deviations, the minimal number of animals needed to analyze and detect difference is $n=6$ per group resulting in an actual power of 0.955 .

\section{Assessment of EAE and Tissue Sample Collection}

The animals were immunized under carbon dioxide $\left(\mathrm{CO}_{2}\right)$ anesthesia with a subcutaneous injection of encephalitogenic emulsion in the right hind hock. The encephalitogenic emulsion contained equal volumes of rat spinal cord homogenate $(50 \% \mathrm{w} / \mathrm{v}$ in phosphate-buffered saline, PBS) and complete Freund's adjuvant (CFA; Sigma, St. Louis, MO, United States), containing $1 \mathrm{mg} / \mathrm{ml}$ of Mycobacterium tuberculosis. Age-matched animals were anesthetized under the same conditions but were not immunized, and they were used as a control group. Animals from both experimental groups were monitored and weighed daily for 28 days after immunization. All animal experiments started at 10:00 a.m. every day. Disease severity was assessed by checking the neurological signs of $\mathrm{EAE}$, following the subsequent scale: 0 -unaffected; 0.5-reduced tail tone; 1-tail atony; 1.5-moderately clumsy gait, impaired righting ability, or combination; 2-hind limb paresis; 2.5-partial hind limb paralysis; 3-complete hind limb paralysis; 3.5-complete hind limb paralysis with forelimb weakness; 4-moribund state; and 5-death. For each time point, average disease score and weight were calculated. When animals had a disease score of 2.5 or higher, they were fed and given water by hand. The animals were euthanized by gradual asphyxia in a $\mathrm{CO}_{2}$ chamber at three time points representing three phases of the disease course: onset (Eo), peak (Ep), and end (Ee) of EAE. Afterward, blood was collected by cardiac puncture and the animals were perfused with $0.9 \%$ saline. The hypothalamic, spinal cord, anterior pituitary, and adrenal gland tissues were quickly dissected on ice. The adrenal gland capsule was removed and the left adrenal was processed for realtime PCR, while the right adrenal was used for oxidative stress analysis. The isolated tissues were further used for RNA isolation and quantitative real-time PCR, Western blot, immunohistochemistry/immunofluorescence, and oxidative stress evaluation. The investigators who performed the gene, protein, and biochemical studies were blinded to the experimental conditions. The timeline of the experiments is presented in Figure 1.

\section{Serological Analysis Corticosterone Measurement}

Corticosterone was measured in the control $(n=6)$ and EAE animals ( $n=6$ /group) in serum acquired from blood samples obtained by cardiac puncture of at least six animals per group. Blood was centrifuged at $3,000 \times g$ for $15 \mathrm{~min}$, and all samples were stored at $-80^{\circ} \mathrm{C}$ before determining corticosterone concentration using the commercially available Corticosterone Parameter Assay Kit (R\&D Systems Inc., Minneapolis, MN, United States). The sensitivity of this kit is $0.047 \mathrm{ng} / \mathrm{ml}$. The plate was read at $450 \mathrm{~nm}$ and wavelength correction was set to $570 \mathrm{~nm}$. To determine the corticosterone level, calculation was performed using a four-parameter logistic curve fitting program.

\section{Prostaglandin Levels}

Serum PGE2 level was determined in the control $(n=6)$ and EAE animals ( $n=6 /$ group) from blood samples gathered by cardiac puncture. Blood was centrifuged at 3,000 $\times g$ for $15 \mathrm{~min}$, and all samples were stored at $-80^{\circ} \mathrm{C}$ before ELISA. The test was completed using a commercial PGE2 ELISA Kit (Invitrogen, Carlsbad, CA, United States) according to the manufacturer's specifications. The absorbance was read at $405 \mathrm{~nm}$ and corrected at $570 \mathrm{~nm}$. The concentrations of PGE2 obtained from the assay were determined by calculation using a four-parameter logistic curve fitting program.

\section{Quantitative Real-Time PCR Analysis}

After isolation, hypothalamic, anterior pituitary, and adrenal gland tissues ( $n=6$ /group) were stored at $-80^{\circ} \mathrm{C}$ in RNAlater ${ }^{\circledR}$ RNA Stabilization Solution (Ambion ${ }^{\mathrm{TM}}$, Applied Biosystems by Thermo Fisher Scientific, Waltham, MA, United States) until all groups were collected. RNA was isolated using RNeasy Mini Kit (QIAGEN, Hilden, Germany) or RNAqueous ${ }^{\circledR}$ Kit $\left(\right.$ Ambion $^{\text {TM }}$, Applied Biosystems by Thermo Fisher Scientific), according to the manufacturer's instructions. The concentration of RNA was assessed by measuring absorbance on Nanophotometer ${ }^{\circledR}$ N60 (Implen, Munich, Germany) at $260 \mathrm{~nm}$, while the purity of the samples was determined by $A_{260} / A_{280}$ and $A_{260} / A_{230}$ ratios. Furthermore, $1 \mu \mathrm{g}$ of RNA was used for reverse transcription, done with High Capacity cDNA Reverse Transcription Kit (Applied Biosystems by Thermo Fisher Scientific). Quantitative real-time PCR analysis (qRT-PCR) was performed using 10 times diluted cDNA samples. QuantStudio ${ }^{\mathrm{TM}} 3$ Real-Time PCR System (Applied Biosystems by Thermo Fisher Scientific) was used for qRT-PCR with Power SYBR ${ }^{\text {TM }}$ Green PCR Master Mix (Applied Biosystems by Thermo Fisher Scientific) and primers were designed on specific targets. The primer sequences were as follows: Pomc, forward: AGAACGCCATCATCAAGAACG, reverse: AGGTCAGGTGCTCTCGCC; Il1 $\beta$, forward: AAACAGCAATGGTCGGGACA, reverse: GTCCGGGAAG GCTGATTAGG; Tnf, forward: CCCCCATTACTCTGACCCCT, reverse: CCCAGAGCCACAATTCCCTT; Nos2, forward: ACACAGTGTCGCTGGTTTGA, reverse: AACTCTGCTGTT CTCCGTGG; Nfe2l2, forward: GACTTGGAATTGCCACCGC, reverse: CCTGTTCCTTCTGGAGTTGCT; M2cr, forward: TCCCACCATATCCCCACAGT, reverse: GGAGCGGGCAA GTAAGAACA; and Gapdh, forward: CAACTCCCTCAA 
A

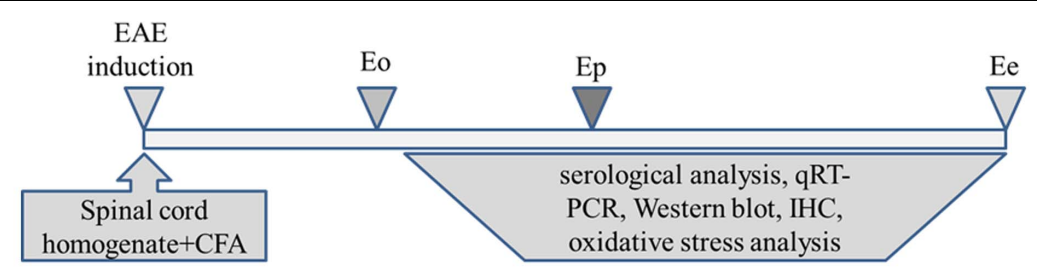

B

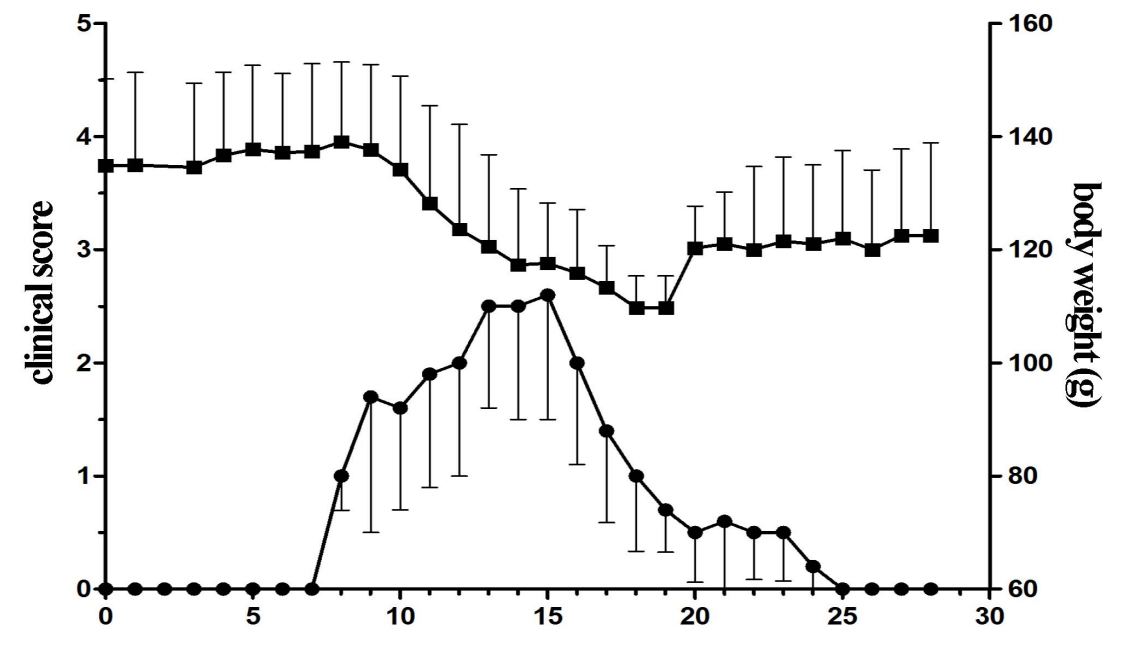

Days post-immunization
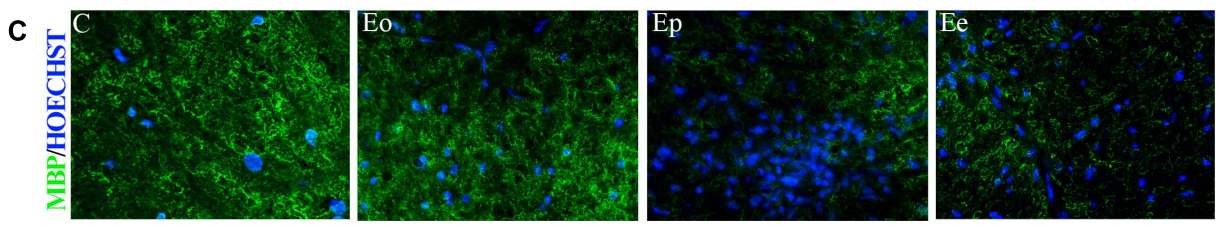

FIGURE 1 | (A) Timeline of the experimental design. Rats were immunized with the homogenate of the spinal cord and CFA. The rats were sacrificed at the onset of the first symptom (Eo), peak of disease (Ep), and end of symptoms (Ee). (B) Time course of experimental autoimmune encephalomyelitis (EAE) symptoms and variation in the weight of the animals. Data have been expressed as mean \pm SEM of daily measurements of each animal. (C) Inflammation was observed using Hoechst stain (blue), while demyelination was detected using the MBP antibody (green fluorescence).

GATTGTCAGCAA, reverse: GGCATGGACTGTGGTCATGA (all from Invitrogen, Carlsbad, CA, United States). The expression levels of the target genes were evaluated by comparing their $C t$-values to $C t$-values of Gapdh from the same sample $\left(2^{-\Delta C t}\right.$ method).

\section{Western Blot}

Isolated anterior pituitary tissue ( $n=6$ /group) was homogenized in RIPA buffer (50 mM Tris pH 7.5, $150 \mathrm{mM} \mathrm{NaCl}, 1 \%$ NP-40, 0.1\% SDS, 10 mM EDTA, 10 mM EGTA, 0.5\% Triton X-100) with protease inhibitors (Roche, Penzberg, Germany). Subsequently, the samples were sonicated two times for $5 \mathrm{~s}$ while kept on ice and centrifuged at $14,000 \times g$ for $30 \mathrm{~min}$ at $4^{\circ} \mathrm{C}$. The resulting supernatants' protein concentration was assessed using the Micro BCA Protein Assay Kit, following the manufacturer's instructions (Thermo Fisher Scientific, Rockford, IL, United States).
The samples were diluted in $4 \times$ Laemmli sample buffer, incubated for $5 \mathrm{~min}$ at $95^{\circ} \mathrm{C}$, and loaded onto $10 \%$ polyacrylamide gel. After electrophoresis, the resolved proteins were transferred to PVDF membranes (Immobilon-P transfer membrane, Millipore, Darmstadt, Germany) for $1 \mathrm{~h}$ at $100 \mathrm{~V}$. The membranes were incubated in $5 \%$ bovine serum albumin (Sigma-Aldrich, Munich, Germany) in Tris-buffered saline (20 mM Tris, pH 7.4, $136 \mathrm{mM} \mathrm{NaCl}$ ) with $0.05 \%$ Tween 20 (TBST), for $1 \mathrm{~h}$ at room temperature, to block unspecific binding. Afterward, the membranes were incubated with primary antibody (rabbit polyclonal antibody) directed against ACTH (obtained from Dr. A. Parlow, National Institute of Diabetes and Digestive and Kidney Diseases, National Hormone and Peptide Program, Torrance, CA, United States) and mouse monoclonal antibody against $\beta$-actin (Sigma-Aldrich, St. Louis, MO, United States) at $4^{\circ} \mathrm{C}$ overnight. On the next day, the membranes were washed three times with TBST and 
incubated with appropriate secondary antibodies conjugated with horseradish peroxidase (HRP) (purchased from Santa Cruz, CA, United States), for $2 \mathrm{~h}$ at room temperature. After washing three times in TBST, the membranes were incubated with SuperSignal ${ }^{\mathrm{TM}}$ West Femto Maximum Sensitivity Substrate (Thermo Fisher Scientific, Waltham, MA, United States), and the bands were visualized on a FluorChem E Digital Imaging System (ProteinSimple, San Jose, CA, United States). ImageJ software package (RRID:SCR_003070) was used for the quantification of the signal and densitometric analysis. The optical density of the target protein was normalized to the optical density of $\beta$-actin of the same lane, and the results are expressed relative to the control group.

\section{Immunohistochemistry}

Pituitary tissues ( $n=6 /$ group) were isolated and fixed in Bouin's solution for $48 \mathrm{~h}$, then dehydrated in a series of alcohol dilutions, immersed in xylene, and embedded in paraffin. The tissues were cut into $3-\mu \mathrm{m}$-thick paraffin sections, and labeling for ACTH was performed. The sections were quickly rinsed in PBS, and then unspecific binding was blocked by incubation of the tissues in 5\% normal donkey serum (Sigma-Aldrich, Munich, Germany). The sections were incubated with rabbit polyclonal antibody directed against ACTH (purchased from Dr. A. F. Parlow, National Hormone and Peptide Program, CA, United States), overnight at $4^{\circ} \mathrm{C}$. After washing in PBS, the sections were incubated with donkey anti-rabbit secondary HRP-conjugated antibody (1:250, Santa Cruz, Santa Cruz Biotechnology, CA, United States) for $2 \mathrm{~h}$ at room temperature. Immunoreactivity was visualized with $3,3^{\prime}$-Sdi-amino-benzidine-tetrahydrochloride (DAB, Dako, Glostrup, Denmark) as substrate. The sections incubated without primary antibodies resulted in the absence of any specific reaction. After dehydration and clearing, the tissue was mounted using DPX Mounting medium (Fluka, Buchs, Switzerland). The slides were examined under a light microscope (Olympus, BX-51, Olympus, Japan) equipped with a microcator (Heidenhain MT1201, Heidenhain, Schaumburg, IL, United States). The stereological analyses were carried out using the new CAST (Computer Aided Stereology Tool) stereological software package (CAST software, Visiopharm, ver. 2.12.1.0, Hørsholm, Denmark), as previously described in detail (Trifunović et al., 2014). Briefly, using unbiased stereological analysis, the anterior pituitary volume and the volume density of ACTH cells were estimated using Cavalieri's principle (Gundersen and Jensen, 1987). Every 20th section was analyzed to determine the stereological parameters of ACTH cells, i.e., about 24 sections for each gland. A fractionator/physical dissector design was used to estimate the number of ACTH cells, while the cell volume was calculated as equivalent to the total volume occupied by ACTH cells divided by their number. The micrographs are captured using a Zeiss Axiovert microscope (Carl Zeiss GmbH, Vienna, Austria).

\section{Immunofluorescence}

The spinal cord tissues were collected in order to perform immunofluorescence analyses. Spinal cords were fixed in 4\% paraformaldehyde in $0.1 \mathrm{M}$ PBS, $\mathrm{pH} 7.4$ for $12 \mathrm{~h}$ at $4^{\circ} \mathrm{C}$.
Cryoprotection of the spinal cord was achieved by tissue immersion into the graded sucrose solutions $(10-30 \%$ in $0.1 \mathrm{M}$ $\mathrm{PBS}, \mathrm{pH}$ 7.4). The lumbar parts were embedded in OCT (Sakura, Japan) in a cryomold. Frozen blocks were further stored at $-80^{\circ} \mathrm{C}$ until sectioning. Coronal sections (20 $\mu \mathrm{m}$ thick) of the lumbar spinal cord were cut and placed on a SuperFrost glass slide. The sections were allowed to dry for $2 \mathrm{~h}$ at room temperature (RT) and stored at $-20^{\circ} \mathrm{C}$ until staining. Sections were first rinsed in PBS and then incubated in normal donkey serum (10\% solution in PBS; Santa Cruz Biotechnology, Santa Cruz, CA, United States) for $1 \mathrm{~h}$ at RT to block unspecific labeling. Incubation with primary antibody for myelin basic protein (MBP 1:100) (BioLegend 801703, RRID:AB_510039) was done overnight at $4^{\circ} \mathrm{C}$. After washing in PBS, the sections were incubated with Alexa Fluor 488 fluorescent antibody. Nuclei were visualized with Hoechst nuclear staining. Sections incubated with appropriate secondary antibodies without the primary antibody were used as negative control. The sections were mounted in Mowiol (Calbiochem, Millipore, Darmstadt, Germany) and captured on Zeiss Axiovert fluorescent microscope (Zeiss, Graz, Austria).

\section{Parameters of Oxidative Stress}

Pituitary and adrenal gland tissues were isolated and homogenized in RIPA buffer with protease inhibitors (Roche, Penzberg, Germany). Then, the samples were sonicated three times for $5 \mathrm{~s}$ and kept on ice. After centrifugation at $14,000 \times g$ for $30 \mathrm{~min}$ at $4^{\circ} \mathrm{C}$, the supernatants were collected and used for the determination of oxidative stress parameters: production of $\mathrm{NO}, \mathrm{O}_{2}{ }^{-}$, malondialdehyde (MDA), and total glutathione content (GSH) and activity of antioxidative enzymes catalase, mitochondrial superoxide dismutase (SOD2), glutathione peroxidase (GPx), and reductase (GSR) as described previously (Bozic et al., 2015).

\section{Determination of NO Production}

NO production was determined using the Griess assay. Since $\mathrm{NO}$ is a volatile molecule, we measured the concentrations of its products, nitrites, and nitrates. Nitrates were first reduced into nitrites by metallic cadmium (Navarro-Gonzálvez et al., 1998), and then total nitrites were quantified spectrophotometrically by the Griess reaction. The Griess reagent was made of $1.5 \%$ sulfanilamide (Sigma-Aldrich, Munich, Germany) in $1 \mathrm{M}$ $\mathrm{HCl}$ and $0.15 \% \mathrm{~N}$-(1-naphthyl) ethylendiamine dihydrochloride (Fluka, Buchs, Switzerland) in distilled water. Known sodium nitrite concentrations were used to generate a standard curve by which the nitrite concentration in the samples was calculated. The results are expressed as mean nitrite concentration $(\mu \mathrm{M} / \mathrm{mg}$ protein) \pm SEM.

\section{Superoxide Anion Radical}

The method based on the reduction of nitroblue tetrazolium (NBT, Sigma-Aldrich, Munich, Germany) to monoformazan by $\mathrm{O}_{2}{ }^{-}$was used for evaluating the concentration of $\mathrm{O}_{2}{ }^{-}$ in the samples. The product of this reaction was measured spectrophotometrically at $550 \mathrm{~nm}$ (Auclair and Voisin, 1985). The results are expressed as mean reduced NBT $(\mu \mathrm{M} / \mathrm{mg}$ protein) \pm SEM. 


\section{Malondialdehyde}

The MDA concentration was evaluated using a spectrophotometric method (Villacara et al., 1989). The samples were incubated with thiobarbituric acid (TBA) reagent (15\% trichloroacetic acid and $0.375 \%$ TBA, water solution, Merck, Darmstadt, Germany) at $95^{\circ} \mathrm{C}$ and $\mathrm{pH}$ 3.5. MDA formed a red product with the TBA reagent, and the absorbance was measured at $532 \mathrm{~nm}$. The results are expressed as the mean concentration of MDA ( $\mathrm{nmol} / \mathrm{mg}$ protein) \pm SEM.

\section{Total Glutathione Content}

Total glutathione content was determined using the DTNBGSSG reductase recycling assay. The formation of 5-thio-2nitrobenzoic acid (TNB), corresponding to total glutathione content in the sample, was measured spectrophotometrically at $412 \mathrm{~nm}$ (Anderson, 1985). Glutathione concentration in the samples was estimated from a standard curve created using known GSSG concentrations. The results are expressed as the mean concentration of glutathione ( $\mathrm{nmol} / \mathrm{mg}$ protein) \pm SEM.

\section{Glutathione Peroxidase Activity}

GPx activity was indirectly measured using spectrophotometric determination of NADPH consumption mediated by GPx, as previously described (Bozic et al., 2015). The results are expressed as the amount of reduced NADPH per mg of total protein in the sample (mol NADPH/mg protein) \pm SEM.

\section{Glutathione Reductase Activity}

GSR catalyzes the reduction of GSSG to GSH by the oxidation of the coenzyme NADPH to $\mathrm{NADP}^{+}$. A decrease in NADPH fluorescence was determined with excitation/emission of $360 / 460 \mathrm{~nm}$. As a standard, we used $100 \mathrm{mM} \mathrm{NAD}^{+}$. The results are expressed as the extent of reduced NADPH $(\mu \mathrm{mol}$ $\mathrm{NADPH} / \mathrm{mg}$ protein) $\pm \mathrm{SEM}$.

\section{Mitochondrial Superoxide Dismutase Activity}

The activity of SOD2 was measured spectrophotometrically by determining a decrease in the rate of the spontaneous epinephrine autoxidation at $480 \mathrm{~nm}$. The kinetics of enzyme activity was measured in $50 \mathrm{mM}$ carbonate buffer $(\mathrm{pH} \mathrm{10.2,}$ containing 0.1 mM EDTA, Serva, Feinbiochemica, Heidelberg, Germany), after the addition of $10 \mathrm{mM}$ epinephrine and $5 \mathrm{mM} \mathrm{KCN}$. The results are expressed as units of enzyme activity per $\mathrm{mg}$ of total protein $(\mathrm{U} / \mathrm{mg}$ ), where one unit represents the amount of enzyme required for $50 \%$ inhibition of autoxidation of epinephrine.

\section{Catalase Activity}

Catalase (CAT) activity was determined spectrophotometrically by measuring the absorbance of the colored complex formed between ammonium molybdate and $\mathrm{H}_{2} \mathrm{O}_{2}$ at $405 \mathrm{~nm}$. The results are expressed as units of CAT activity per $\mathrm{mg}$ of total protein $(\mathrm{U} / \mathrm{mg})$, where one unit is the amount of $\mathrm{H}_{2} \mathrm{O}_{2}$ reduced per min ( $\mu \mathrm{M} \mathrm{H}_{2} \mathrm{O}_{2} / \mathrm{min}$ ).

\section{Statistical Analysis}

Statistical analysis was performed in GraphPad Prism 5 software (RRID:SCR_002798, GraphPad Software, La Jolla, CA,
United States). No test for outliers was performed. All statistical analyses were performed by researchers who were unaware of the animals' group. The results were tested for Gaussian distribution with the Kolmogorov-Smirnov normality test. If the groups had passed the normality test, the significance of the difference in the means between groups was calculated by one-way ANOVA (followed by Dunnett's post hoc test). Otherwise, the Kruskal-Wallis test followed by Dunnett's post hoc test was performed. Results are expressed as mean values \pm SEM and values of $p<0.05$ were considered to be statistically significant.

\section{RESULTS}

\section{Disability Score Coincides With Weight Loss in the Course of EAE}

Female DA rats generated acute, monophasic disease after priming for EAE using homologous spinal cord tissue homogenate combined with CFA (Figure 1A). The first clinical deficit associated with EAE (flaccid tail) appeared between 8 and $10 \mathrm{dpi}$ (Eo) and reached the peak of the symptoms (Ep) around $15 \mathrm{dpi}$. The development of neurological deficit was accompanied by a rapid and substantial ( 20\%) weight loss. At $20 \mathrm{dpi}$, rats started to recover and gain weight. The absence of symptoms was evident at $25 \mathrm{dpi}$ (Ee). All immunized rats developed a clinical score above 1 , with a maximal severity score around 3 (Figure 1B). The clinical symptoms are followed by histopathological changes, inflammation, and demyelination. The most pronounced inflammation, judged by Hoechst staining, was observed at the peak of EAE and the observed inflammation-induced demyelination was seen by MBP staining (Figure 1C). Little inflammation/demyelination was observed at the onset and end of EAE.

\section{POMC and ACTH Showed Different Expression Patterns During EAE}

We examined the alterations in transcript and protein levels of POMC and ACTH in the hypothalamus and pituitary at different stages of EAE (Figure 2A). The level of Pomc mRNA in the hypothalamus decreased significantly at Eo when compared with naive animals (Figure 2A). In contrast, a strong induction of Pomc mRNA level in the anterior pituitary was demonstrated at the Eo and Ep when compared with naive animals. Next, we evaluated the protein expression pattern of POMC and ACTH in the pituitary during EAE. Densitometric analysis of Western blot revealed a significant increase in POMC and ACTH protein expression at the peak of EAE (Figure 2B).

\section{Histological and Stereological Parameters of Corticotrophs During EAE}

Our next set of experiments aimed to investigate the pattern of tissue expression of ACTH. In all experimental animals, ACTH-immunopositive cells were irregularly shaped and located individually or in groups, between the capillaries 
A
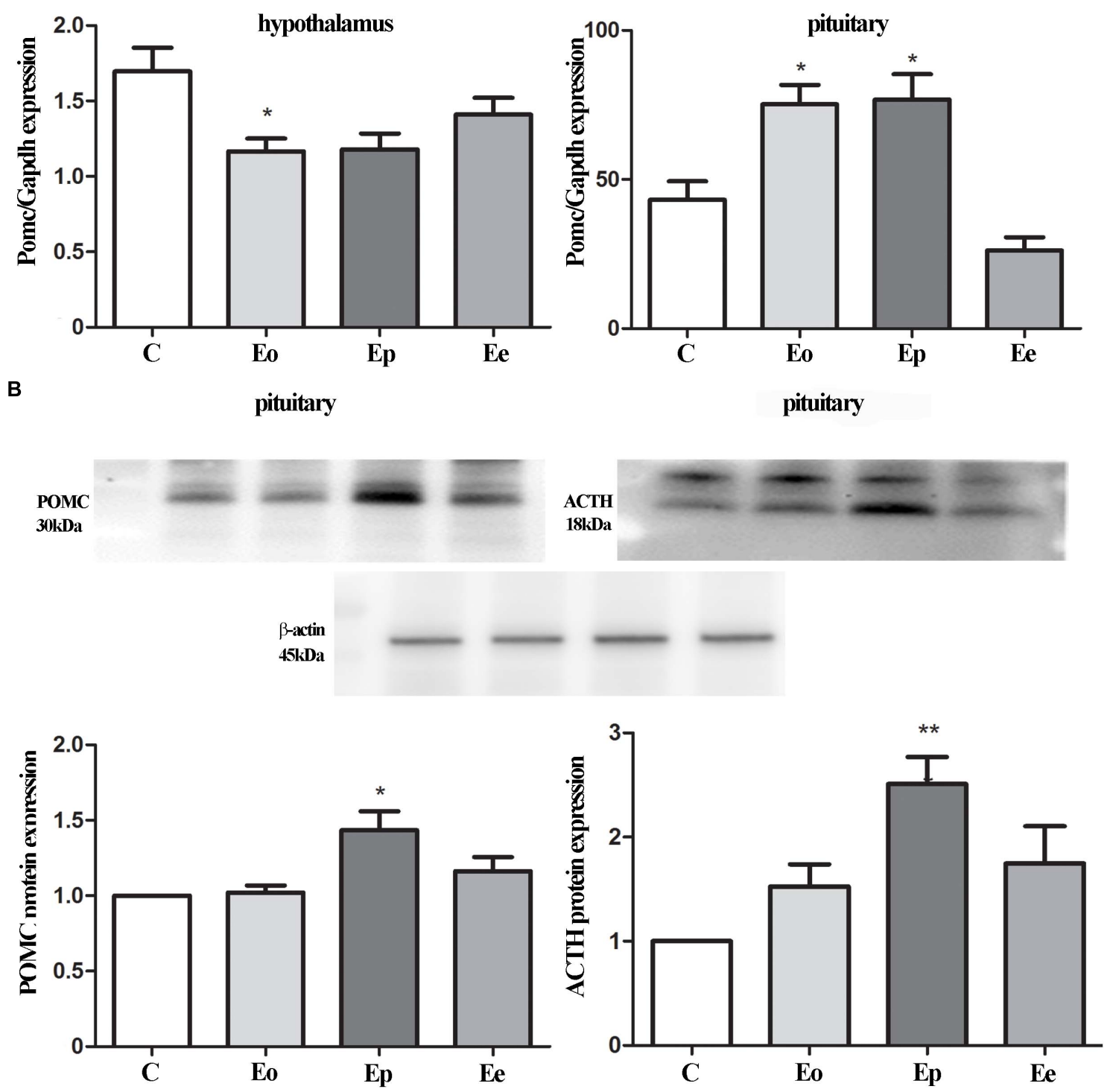

FIGURE 2 | (A) POMC gene expressions were assessed by qRT-PCR in immunized (Eo, Ep, and Ee) and control animals (C-control), with Gapdh as an internal reference standard in the hypothalamus and pituitary. (B) Protein levels of POMC and adrenocorticotropic hormone (ACTH) relative to $\beta$-actin in the pituitary were determined using the Western blot method and results are expressed as mean\% of control values \pm SEM. ${ }^{*} p<0.05$; ${ }^{* *} p<0.001$ compared with the control.

in the pituitary pars distalis. Most of them were stellate, polygonal, or oval, with a round nucleus. The corticotrophs during EAE outnumbered in comparison with the control group (Figure 3).

The pituitary weight and volume decreased in Eo $(7.6 \mathrm{mg}$; $\left.2.7 \mathrm{~mm}^{3}\right)$ and $\mathrm{Ep}\left(8.8 \mathrm{mg} ; 3.1 \mathrm{~mm}^{3}\right)$ in comparison with the control (9.4 mg; $3.7 \mathrm{~mm}^{3}$ ), while pituitary weight in Ee $(9.2 \mathrm{mg}$; $2.6 \mathrm{~mm}^{3}$ ) (Figure 4A) tented to match the control values. The stereological analysis of the volume density of ACTH cells revealed a significant increase by 80 and $70 \%$ in Eo and Ep in comparison with the control group, respectively (Figure 4B). The number of ACTH cells increased in Eo, Ep, and Ee compared with the control values (Figure 4C). However, the volume density of a single ACTH cell shows a significant increase only in Ep when compared with the control rats (Figure 4D).

\section{Inflammation and Oxidative Parameters in Pituitary and Adrenal Glands During EAE}

Next, we aimed at elucidating the effects of EAE in pituitary and adrenal glands of DA rats. Also, we checked the inflammation status in the serum of control and EAE animals. EAE induces a double increase in PGE2 concentration at the onset of EAE and maintains higher levels of PGE2 at Ep and Ee when compared with the control animals (Table 1). Because glucocorticoids 

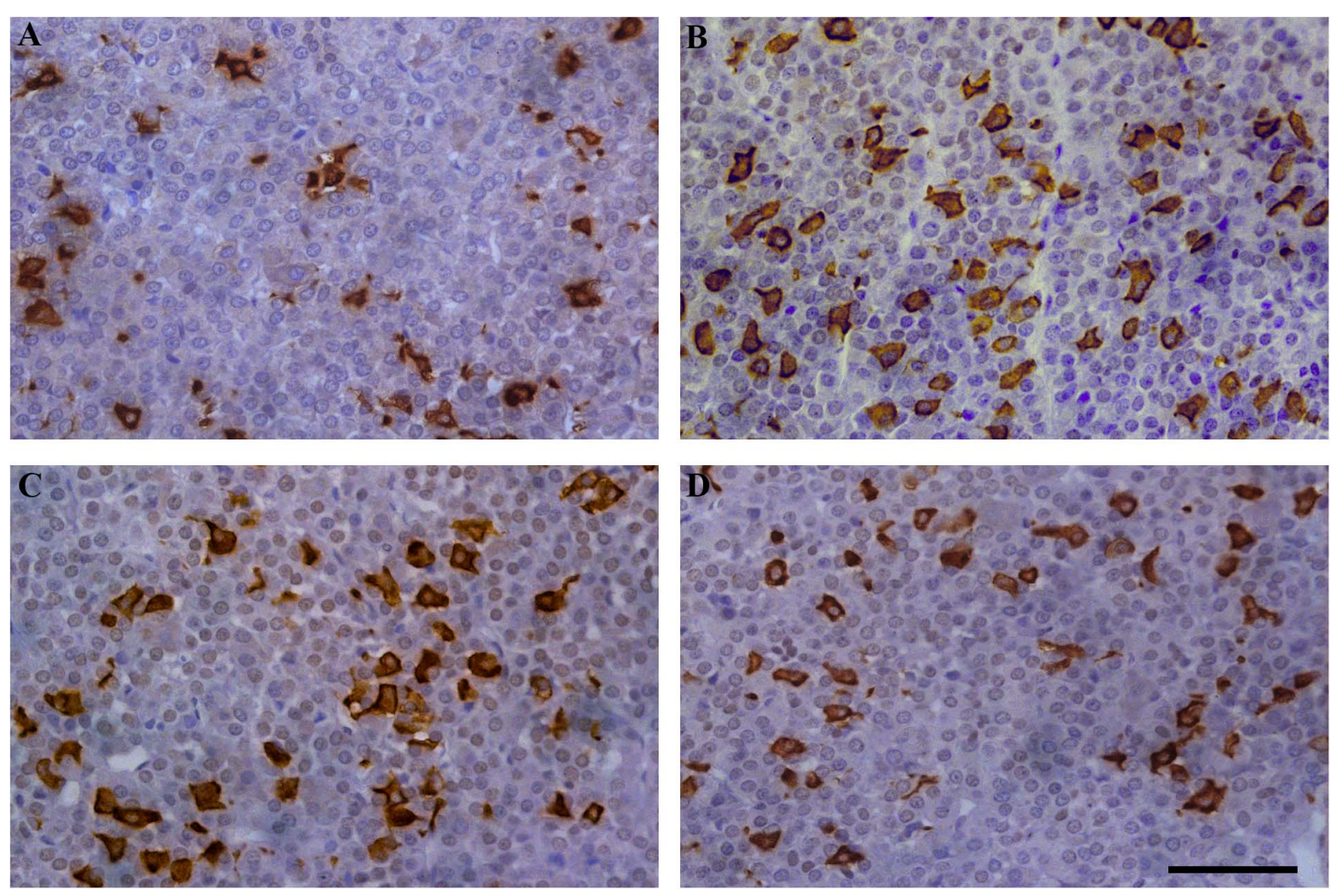

FIGURE 3 | Temporal changes in the immunoreactivity of ACTH cells during EAE. Pituitary glands were obtained from rats afflicted with EAE, (A) control rat, and EAE rats sacrificed at onset (B), peak (C), and end of the disease (D). Scale bar $50 \mu \mathrm{m}$.

have been closely associated with the onset and severity of EAE, we measured corticosterone serum levels as well. As expected, EAE induced a significant and almost double increase in serum corticosterone levels at the peak of EAE $(983.8 \pm 101.4$ $\mathrm{ng} / \mathrm{ml})$ in comparison with the control animals $(541 \pm 94.5$ $\mathrm{ng} / \mathrm{ml}$ ) (Table 1).

Tnf expression was significantly upregulated at the peak of EAE in the pituitary when compared with the control animals, while Il $1 \beta$ remains unaltered throughout EAE. Nfe2l2 expression was upregulated (twofold increase) at the peak of EAE. The increased expression of Nos2 (almost two times in comparison with the control rats) was recorded at the onset of EAE. Afterward, the Nos2 expression levels return to control levels (Table 1). This fact correlated with a higher $\mathrm{NO}, \mathrm{O}_{2}{ }^{-}$, and lipid peroxidation rate at the onset and peak of the EAE in the pituitary (Figure 5).

In the adrenal glands, an upregulation of $M c 2 r$ expression was detected at the peak of EAE. Furthermore, a significant increase in superoxide anion and MDA that occurred during EAE was observed (Figure 6). Assessment of glutathione metabolism parameters revealed reduced levels of GSH and GSR in the pituitary at the onset and peak of EAE, while GPx levels remain unaltered during EAE (Figure 5). The GSH levels decreased in the adrenal glands during EAE (Figure 6). Catalase levels decreased at the peak of EAE in both the pituitary and adrenal glands (Figures 5, 6). Despite increased SOD2 activities in the pituitary (Figure 5), the same enzymatic activity was unaffected in the adrenal glands during EAE (Figure 6).

\section{DISCUSSION}

This study outlines the findings related to the activity of the HPA axis during EAE in female DA rat strain. It points and connects alterations in the pituitary and adrenal glands concerning inflammation and oxidative stress. It was previously shown that DA rats manifest a blunted HPA response, thus are prone to EAE induction (Stefferl et al., 1999). In our study, EAE developed a predictable acute monophasic course of the illness (Bjelobaba et al., 2018), accompanied by welldefined neurological impairment attributable to inflammation and demyelination (Lavrnja et al., 2008; Jakovljevic et al., 2017). Previous observations made in a mouse model of EAE revealed that PGE2 acts as a mediator of acute inflammation during the pathogenesis of EAE (Esaki et al., 2010). It was also shown that PGE2 in cooperation with cytokines may amplify their actions by making a positive feedback loop and facilitate acquired immunity-induced long-lasting inflammation (Kihara et al., 2009; Yao et al., 2009). Indeed, we here observe a strong, significant induction of PGE2 in serum at the onset of EAE, which remains high throughout the disease. The increased PGE2 levels may control the overactivated HPA axis, mainly through 


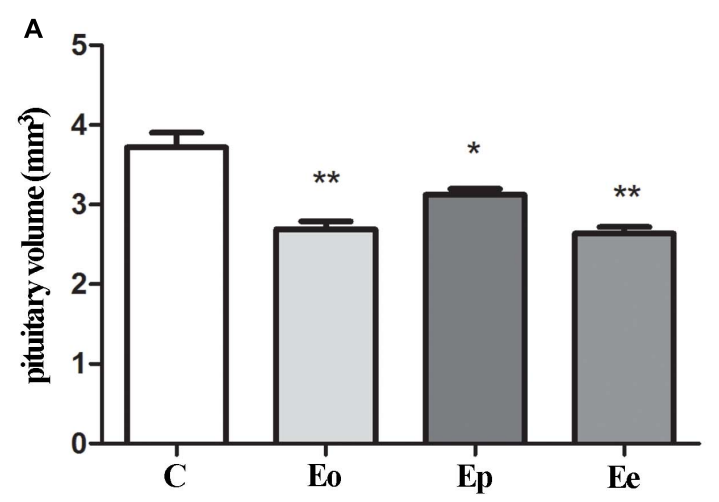

C

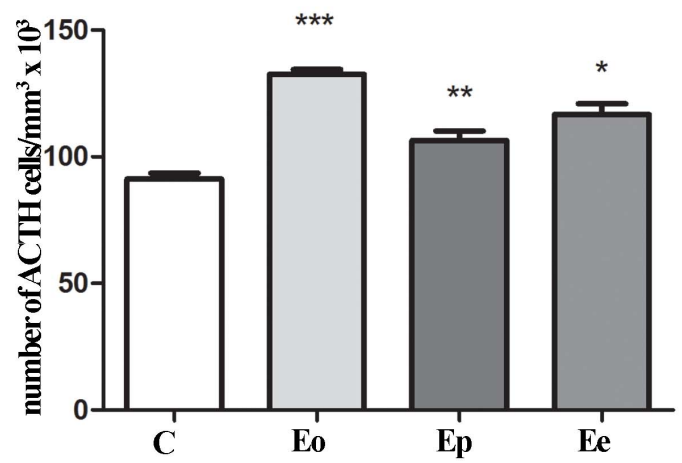

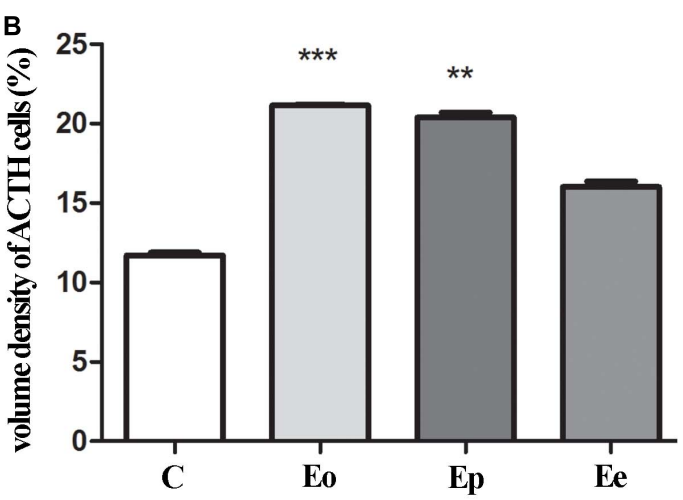

D

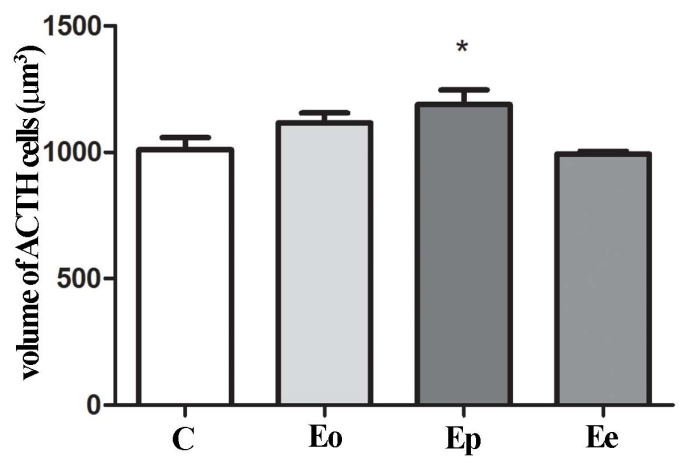

FIGURE 4 | Stereological analysis of the temporal changes of ACTH cells. (A) Changes in the volume of the pituitary during EAE. Variation of ACTH secreting cells in the pituitary in volume density (B), number (C), and volume of the single cell (D) in the course of EAE. Pituitary from control - C and EAE rats, obtained from different time points-Eo (onset of the disease), Ep (peak of the disease), and Ee (end of the disease), and used for determination in morphometric parameters. Results are given as means \pm SEM; ${ }^{*} p<0.05,{ }^{* \star} p<0.01$, and ${ }^{\star * *} p<0.001$ on a corresponding day.

TABLE 1 | Inflammatory and oxidative parameters during EAE.

\begin{tabular}{|c|c|c|c|c|}
\hline & Ctrl & Eo & Ep & Ee \\
\hline PGE2 (pg/ml)-serum & $1213.2 \pm 107.8$ & $2445.0 \pm 188.6^{\star \star}$ & $2165.0 \pm 108.7$ & $1759.5 \pm 55.7$ \\
\hline Corticosterone(ng/ml)-serum & $541 \pm 94.5$ & $595.8 \pm 74.2$ & $983.8 \pm 101.4^{\star}$ & $827.96 \pm 85.8$ \\
\hline $\operatorname{Tnf}(\Delta \mathrm{Ct})$-pituitary & $0.32 \pm 0.08$ & $0.29 \pm 0.04$ & $0.43 \pm 0.03^{\star}$ & $0.32 \pm 0.05$ \\
\hline$\| 1 \beta(\Delta \mathrm{Ct})$-pituitary & $0.51 \pm 0.11$ & $0.48 \pm 0.1$ & $0.47 \pm 0.06$ & $0.26 \pm 0.12$ \\
\hline Nos2 ( $\Delta \mathrm{Ct}$ )-pituitary & $0.21 \pm 0.018$ & $0.395 \pm 0.06^{\star \star}$ & $0.177 \pm 0.09$ & $0.159 \pm 0.06$ \\
\hline$N f e 2 / 2(\Delta \mathrm{Ct})$ - pituitary & $22.37 \pm 1.92$ & $20.3 \pm 7.23$ & $43.51 \pm 5.85^{\star}$ & $28.5 \pm 6.05$ \\
\hline $\mathrm{M} 2 \mathrm{Cr}(\Delta \mathrm{Ct})$-adrenal gland & $23.4 \pm 2.3$ & $30.4 \pm 3.4$ & $36.5 \pm 1.9^{\star \star}$ & $30.4 \pm 2.7$ \\
\hline
\end{tabular}

${ }^{*} p<0.05,{ }^{* *} p<0.01$ in respect to control, Kruskal-Wallis with Dunn's post hoc test.

high corticosterone levels that act through a negative feedback loop and prevent overproduction of inflammatory molecules (Rivest, 2010).

HPA hormones have a role in the maintenance of body homeostasis, regulation of the immune system, and neuroprotection, which emphasize the importance of adequate HPA response during EAE in order to help the system to overcome disease. Previously, we have shown that EAE induces inflammation in the hypothalamus (Milosevic et al., 2020), which can activate the HPA axis. This, however, does not seem to affect gene expression in the hypothalamus. A slight decrease was observed in Pomc expression during EAE, as was recently shown
(Tanaka et al., 2020), suggesting that the observed weight loss in EAE may not be mediated by this anorectic peptide. Feeding behavior may thus rather be inhibited by proinflammatory cytokines, like IL-1 $\beta$, and TNF- $\alpha$ (Sarraf et al., 1997; Milosevic et al., 2020). The status of the hypothalamus also implies that the observed increase in the pituitary Pomc expression, as well as the protein content of POMC and ACTH, may be associated to the high levels of proinflammatory cytokines, as previously suggested (Harbuz et al., 1992). We have here shown that EAE induces the upregulation of proinflammatory cytokine $\operatorname{Tnf}$ that can further activate oxidative pathways and induce the expression of Nos2. Previously, we have reported increased proinflammatory 

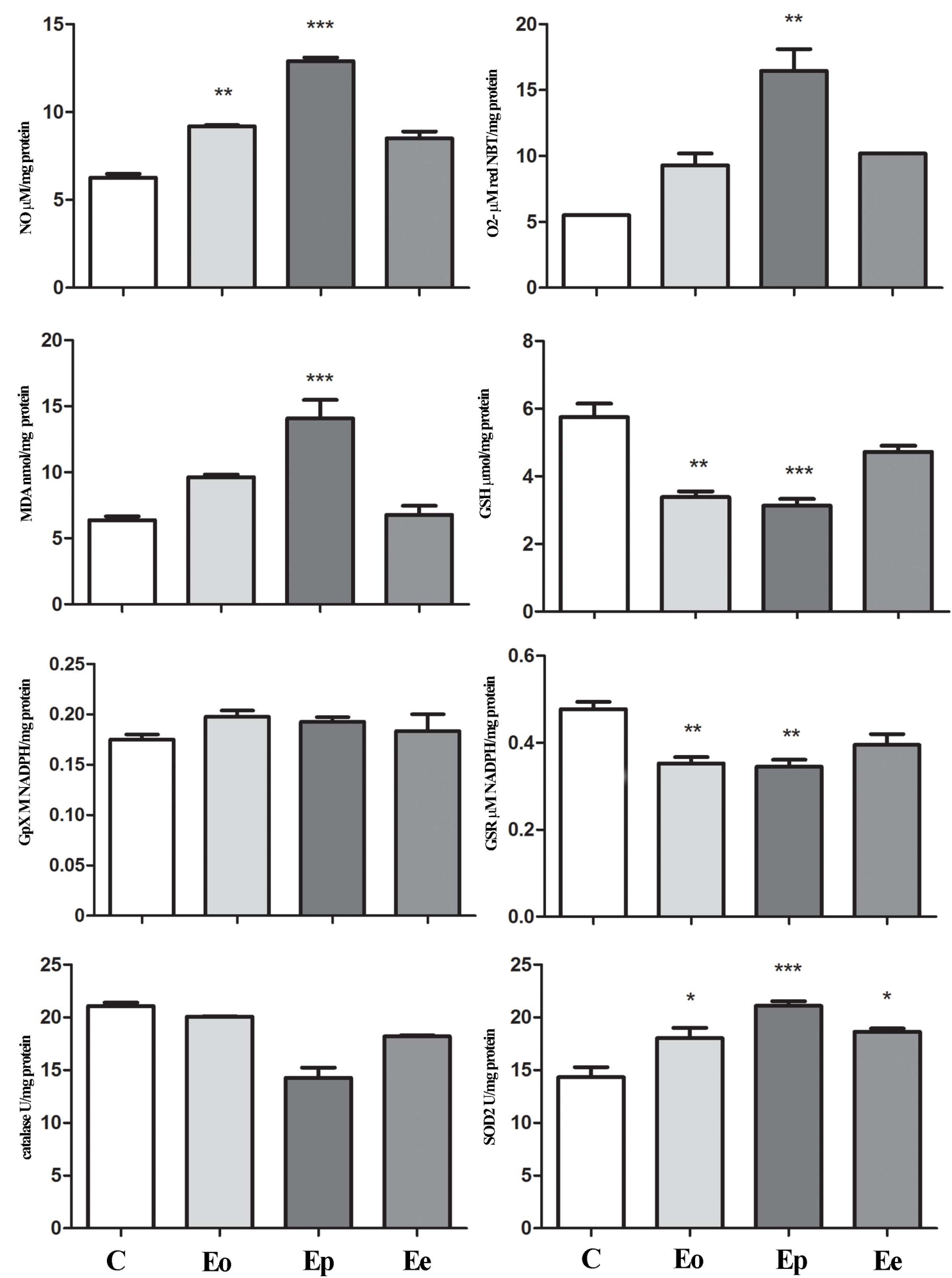

FIGURE 5 | Nitrosative/oxidative status assessment in the pituitary gland during EAE. Total nitrites (NOx; $\mu \mathrm{mol} / \mathrm{mg}$ protein) were determined to assess nitrosative status. For oxidative status assessment, $\mathrm{O}_{2}{ }^{-}$( $\mu \mathrm{mol} / \mathrm{min} / \mathrm{mg}$ protein), GSH ( $\mu \mathrm{mol} / \mathrm{mg}$ protein), and MDA (nmol/mg protein) levels and enzymatic activities of GPx (M $\mathrm{NADPH} / \mathrm{mg}$ protein), GSR ( $\mu \mathrm{mol} \mathrm{NADPH} / \mathrm{mg}$ protein), catalase (U/mg protein), and SOD2 (U/mg protein) were determined in the pituitary gland at the onset (Eo), peak (Ep), and end (Ee) of EAE rats. Values are presented as means \pm SEM. ${ }^{\star} p<0.05,{ }^{\star \star} p<0.01$, ${ }^{\star \star *} p<0.001$ statistically significant difference compared with the control (C) group. 

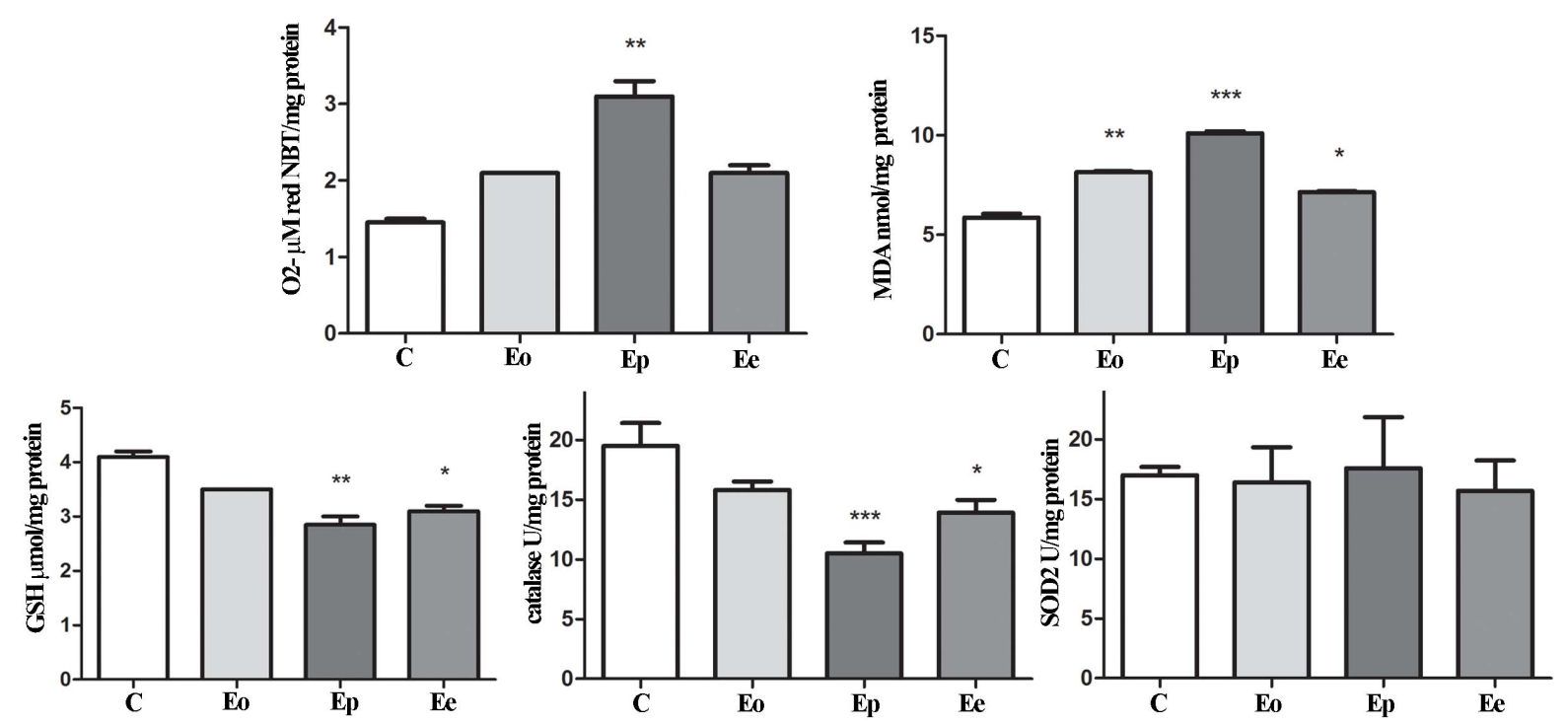

FIGURE 6 | Oxidative and lipid peroxidation status assessment in the adrenal glands of rats during EAE. To assess the oxidative status, $\mathrm{O}_{2}{ }^{-}$( $\mu \mathrm{mol} / \mathrm{min}_{\mathrm{m}} \mathrm{mg}$ protein), GSH ( $\mu \mathrm{mol} / \mathrm{mg}$ protein), and MDA (nmol/mg protein) levels were determined and catalase (U/mg protein) and SOD2 (U/mg protein) activities were assayed in the adrenal gland at the onset (Eo), peak (Ep), and end (Ee) of EAE. Values are presented as means \pm SEM. ${ }^{*} p<0.05$, ${ }^{* \star} p<0.01$, and ${ }^{\star \star *} p<0.001$ statistically significant difference compared with the control (C) group.

cytokines and iNOS at the periphery and in the CNS tissue during EAE, all leading to massive inflammation and demyelination (Lavrnja et al., 2008; Jakovljevic et al., 2019). In our experimental settings, iNOS was upregulated in the pituitary at the onset of EAE. This may result in the observed accumulation of ROS/RNS, such as superoxide anion and nitric oxide at the symptomatic stages of EAE in the pituitary. These ROS/RNS exhibit increased levels at the onset and peak of EAE in the pituitary, returning to control levels at the end of EAE. Together, these highly reactive compounds can attack phospholipids from the membrane and cause cell damage by lipid peroxidation. Indeed, MDA levels significantly increased at the peak of EAE in the pituitary gland, pointing to amplified changes in lipoperoxidation that reflect an alteration in both structural and functional status of this organ. Lipid peroxidation involves the formation and propagation of lipid radicals, the uptake of oxygen, and the rearrangement of the double and unsaturated lipids, resulting in a variety of destroyed products that trigger devastation of membrane lipids (Ayala et al., 2014). The described results imply that pituitary corticotrophs are activated, which is confirmed by the observed increase in volume density and number of ACTH cells. The possible changes in plasma membrane integrity might take place precisely in these cells (corticotrophs). Furthermore, during EAE, the pituitary is evidently under low antioxidant status, judged by the measurements of GSH content, and GSR and CAT activity in the EAE groups is an indication of oxidative stress. Besides its other role, NADPH provides the reducing equivalents for biosynthetic reactions and the oxidation-reduction involved in the protection against ROS toxicity, by upgrading the regeneration of the main antioxidant-glutathione (Espinosa-Diez et al., 2015). A decrease of NADPH in the pituitary indicates a weakened pool of reduced equivalents necessary to provide the redox homeostasis in EAE.
Interestingly, although majority of the analyzed parameters clearly indicate oxidative stress induction in the pituitary during EAE, SOD2 as a central enzyme of antioxidant defense system (Birben et al., 2012) showed an increase in activity at the peak of EAE. Literature data have shown that increased SOD2 levels might be mediated by the nuclear factor (erythroid-derived-2)like 2 factor (Nrf2) pathway (Miljković and Spasojević, 2013). The Nrf2 pathway is a critical mechanism that upregulates antioxidative enzymes and proteins directed toward redox restitution (Kobayashi et al., 2004). It was shown that the absence of Nrf2 aggravates EAE (Johnson et al., 2010), inducing oxidative stress development. In line with that view, Nrf2 upregulation is considered to be responsible for restored oxidative balance in the pituitary gland after EAE induction (Spiers et al., 2015). We have shown its upregulation at the mRNA level in the pituitary at the peak of EAE. Literature data have shown that mitochondrial ROS may activate Nrf2, usually through protein kinases, inducing the expression of antioxidant genes, but also genes controlling mitochondrial quality/quantity (Kasai et al., 2020).

Previous studies showed that EAE increased ACTH levels which activates the Mc2r in the zona fasciculata of the adrenal cortex (Smith and Vale, 2006) and subsequently promotes de novo synthesis and release of corticosterone (Harbuz et al., 1993; Spiga et al., 2011). In this study, we also demonstrate the increased $M c 2 r$ expression in the adrenal glands at the peak of EAE accompanied by increased serum levels of corticosterone at the peak of EAE, as was previously shown in other strains of animals (Stefferl et al., 1999; Esquifino et al., 2004). Endogenous corticosterone inhibits innate and adaptive responses, mainly through reducing lymphocyte proliferation and inhibiting cytokine and antibody production (Webster Marketon and Glaser, 2008), thus ameliorating the clinical score 
of EAE (Sorrells and Sapolsky, 2007). Indeed, adrenalectomy in EAE induced massive peripheral inflammation, underpinning the importance of circulating glucocorticoids in preventing inflammation (Mason et al., 1990; Smith et al., 1996). High plasma cortisol levels and elevated HPA activation were also recorded in MS patients (Melief et al., 2013). Admittedly, it was proposed that in MS, the sensitivity of immune cells to glucocorticoids is impaired, most prominently in patients with the relapsing-remitting disease (Gold et al., 2012).

While many studies were centered on the role of glucocorticoids in MS/EAE, the knowledge on the status of adrenal gland tissue is still quite limited. The adrenal cortex is endowed with high levels of enzymatic and non-enzymatic antioxidants, which are able to handle the enhanced risk factors for oxidative stress. During EAE, we have shown increased $\mathrm{O}_{2}{ }^{-}$ production and MDA concentration at the peak of EAE, implying changes at the membrane of cells in the adrenal gland. Also, GSH content and catalase activity decreased at the peak and end of the EAE compared with control values, while no significant change between the groups was observed considering SOD2 activity. The glutathione redox cycle merges GSH and GSH-associated enzymes and has a crucial antioxidative defense role in neuronal tissue (Forman et al., 2009). EAE induction significantly reduced GSH content at the peak and end of EAE compared with controls. Glutathione scavenges free radicals through non-enzymatic and/or enzymatically catalyzed reactions when it becomes converted immediately into its disulfide form, GSSG, which becomes efficiently reduced back to GSH (Forman et al., 2009).

\section{CONCLUSION}

This study revealed a strong imbalance in the redox system in pituitary and adrenal glands, which may be involved in the observed activation of the HPA axis obtained in our experiments. The HPA activation was followed by an increased number and

\section{REFERENCES}

Anderson, M. E. (1985). Determination of glutathione and glutathione disulfide in biological samples. Meth. Enzymol. 113, 548-555. doi: 10.1016/s0076-6879(85) 13073-9

Auclair, C., and Voisin, E. (1985). "Nitroblue-tetrazolium reduction," in Handbook of Methods for Oxygen Radical Research, eds R. A. Greenwald, (Boca Raton: CRC Press), 123-132.

Ayala, A., Muñoz, M. F., and Argüelles, S. (2014). Lipid peroxidation: production, metabolism, and signaling mechanisms of malondialdehyde and 4-hydroxy-2nonenal. Oxid. Med. Cell. Longev. 2014:360438.

Bellavance, M.-A., and Rivest, S. (2014). The HPA - immune axis and the immunomodulatory actions of glucocorticoids in the brain. Front. Immunol. 5:136. doi: 10.3389/fimmu.2014.00136

Berg, D., Youdim, M. B. H., and Riederer, P. (2004). Redox imbalance. Cell Tissue Res. 318, 201-213.

Beuschlein, F., Fassnacht, M., Klink, A., Allolio, B., and Reincke, M. (2001). ACTHreceptor expression, regulation and role in adrenocortial tumor formation. Eur J. Endocrinol. 144, 199-206. doi: 10.1530/eje.0.1440199

Birben, E., Sahiner, U. M., Sackesen, C., Erzurum, S., and Kalayci, O. (2012). Oxidative stress and antioxidant defense. World Allergy Organ. J. 5, 9-19. volume of corticotrophs in the pituitary at the peak of EAE. The increased gene and protein levels of POMC and ACTH in the pituitary lead to increased corticosterone levels. We may conclude that HPA activation during EAE is associated with the increase of ROS at the pituitary and adrenal levels.

\section{DATA AVAILABILITY STATEMENT}

The raw data supporting the conclusions of this article will be made available by the authors, without undue reservation.

\section{ETHICS STATEMENT}

The animal study was reviewed and approved by the Ministry of Agriculture, Forestry and Water Economy of the Republic of Serbia (permit no. 323-07-05970/2020-05).

\section{AUTHOR CONTRIBUTIONS}

ST, NR, DL, and IL conceived and designed the experiments. IS, AM, MJak, IBo, IBj, DS, and KT performed the experiments. ST, IS, MJan, and IL analyzed the data. MJan, IBj, and IL contributed to the writing of the manuscript. All authors contributed to different aspects of this work, such as the experimental design and the acquisition, analysis, and interpretation of data; finally approved the submitted version of the manuscript; and agreed to be amenable to all aspects of the work.

\section{FUNDING}

This work was supported by the Ministry of Education, Science and Technological Development, the Republic of Serbia, contract No. 451-03-9/2021-14/200007.

Bjelobaba, I., Begovic-Kupresanin, V., Pekovic, S., and Lavrnja, I. (2018). Animal models of multiple sclerosis: focus on experimental autoimmune encephalomyelitis. J. Neurosci. Res. 96, 1021-1042. doi: 10.1002/jnr. 24224

Bjelobaba, I., Savic, D., and Lavrnja, I. (2017). Multiple sclerosis and neuroinflammation: the overview of current and prospective therapies. Curr. Pharm. Des. 23, 693-730. doi: 10.2174/138161282266616121415 3108

Bozic, I., Savic, D., Stevanovic, I., Pekovic, S., Nedeljkovic, N., and Lavrnja, I. (2015). Benfotiamine upregulates antioxidative system in activated BV-2 microglia cells. Front. Cell. Neurosci. 9:351. doi: 10.3389/fncel.2015.00351

Brown, D. I., and Griendling, K. K. (2015). Regulation of signal transduction by reactive oxygen species in the cardiovascular system. Circ. Res. 116, 531-549. doi: $10.1161 /$ circresaha.116.303584

Chapman, K., Holmes, M., and Seckl, J. (2013). 11ß-Hydroxysteroid dehydrogenases: intracellular gate-keepers of tissue glucocorticoid action. Physiol. Rev. 93, 1139-1206. doi: 10.1152/physrev.00020.2012

Dallman, M. F., Akana, S. F., Cascio, C. S., Darlington, D. N., Jacobson, L., and Levin, N. (1987). Regulation of ACTH secretion: variations on a theme of B. Recent Prog. Horm. Res. 43, 113-173. doi: 10.1016/b978-0-12-571143-2.50 010-1 
dos Santos, N., Novaes, L. S., Dragunas, G., Rodrigues, J. R., Brandão, W., Camarini, R., et al. (2019). High dose of dexamethasone protects against EAEinduced motor deficits but impairs learning/memory in C57BL/6 mice. Sci. Rep. 9:6673.

Esaki, Y., Li, Y., Sakata, D., Yao, C., Segi-Nishida, E., Matsuoka, T., et al. (2010). Dual roles of PGE2-EP4 signaling in mouse experimental autoimmune encephalomyelitis. Proc. Natl. Acad. Sci. U. S. A. 107, 12233-12238. doi: 10. 1073/pnas.0915112107

Espinosa-Diez, C., Miguel, V., Mennerich, D., Kietzmann, T., Sánchez-Pérez, P., Cadenas, S., et al. (2015). Antioxidant responses and cellular adjustments to oxidative stress. Redox. Biol. 6, 183-197. doi: 10.1016/j.redox.2015.07.008

Esquifino, A. I., Cano, P., Jiménez, V., Cutrera, R. A., and Cardinali, D. P. (2004). Experimental allergic encephalomyelitis in male Lewis rats subjected to calorie restriction. J. Physiol. Biochem. 60, 245-252. doi: 10.1007/bf03167069

Forman, H. J., Zhang, H., and Rinna, A. (2009). Glutathione: overview of its protective roles, measurement, and biosynthesis. Mol. Aspects Med. 30, 1-12. doi: 10.1016/j.mam.2008.08.006

George, M., Eftychia, I. K., and Maria, M. (2006). Corticotropin releasing hormone and the immune/inflammatory response. Eur. J. Endocrinol. 155(suppl_1), S77-S84.

Gold, S. M., Raji, A., Huitinga, I., Wiedemann, K., Schulz, K. H., and Heesen, C. (2005). Hypothalamo-pituitary-adrenal axis activity predicts disease progression in multiple sclerosis. J. Neuroimmunol. 165, 186-191. doi: 10.1016/ j.jneuroim.2005.04.014

Gold, S. M., Sasidhar, M. V., Lagishetty, V., Spence, R. D., Umeda, E., Ziehn, M. O., et al. (2012). Dynamic development of glucocorticoid resistance during autoimmune neuroinflammation. J. Clin. Endocrinol. Metab. 97, E1402-E1410.

Goodin, D. S. (2014). "Chapter 21 - glucocorticoid treatment of multiple sclerosis," in Handbook of Clinical Neurology, Vol. 122, ed. D. S. Goodin (Amsterdam: Elsevier), 455-464. doi: 10.1016/b978-0-444-52001-2.00020-0

Grasser, A., Moller, A., Backmund, H., Yassouridis, A., and Holsboer, F. (1996). Heterogeneity of hypothalamic-pituitary-adrenal system response to a combined dexamethasone-CRH test in multiple sclerosis. Exp. Clin. Endocrinol. Diabetes 104, 31-37. doi: 10.1055/s-0029-1211419

Gundersen, H. J., and Jensen, E. B. (1987). The efficiency of systematic sampling in stereology and its prediction. J. Microsc. 147(Pt 3), 229-263. doi: 10.1111/j. 1365-2818.1987.tb02837.x

Harbuz, M. S., Leonard, J. P., Lightman, S. L., and Cuzner, M. L. (1993). Changes in hypothalamic corticotrophin-releasing factor and anterior pituitary pro-opiomelanocortin mRNA during the course of experimental allergic encephalomyelitis. J. Neuroimmunol. 45, 127-132. doi: 10.1016/0165-5728(93) 90172-u

Harbuz, M. S., Stephanou, A., Sarlis, N., and Lightman, S. L. (1992). The effects of recombinant human interleukin (IL)-1 alpha, IL-1 beta or IL-6 on hypothalamo-pituitary-adrenal axis activation. J. Endocrinol. 133, 349-355. doi: $10.1677 /$ joe. 0.1330349

Herman, J. P., and Tasker, J. G. (2016). Paraventricular hypothalamic mechanisms of chronic stress adaptation. Front. Endocrinol. 7:137. doi: 10.3389/fendo.2016. 00137

Huitinga, I., Erkut, Z. A., van Beurden, D., and Swaab, D. F. (2003). The hypothalamo-pituitary-adrenal axis in multiple sclerosis. Ann. N. Y. Acad. Sci. 992, 118-128. doi: 10.1111/j.1749-6632.2003.tb03143.x

Jakovljevic, M., Lavrnja, I., Bozic, I., Milosevic, A., Bjelobaba, I., Savic, D., et al. (2019). Induction of NTPDase1/CD39 by reactive microglia and macrophages is associated with the functional state during EAE. Front. Neurosci. 13:410. doi: 10.3389/fnins.2019.00410

Jakovljevic, M., Lavrnja, I., Bozic, I., Savic, D., Bjelobaba, I., Pekovic, S., et al. (2017). Down-regulation of NTPDase2 and ADP-sensitive P2 purinoceptors correlate with severity of symptoms during experimental autoimmune encephalomyelitis. Front. Cell. Neurosci. 11:333. doi: 10.3389/fncel.2017. 00333

Johnson, D. A., Amirahmadi, S., Ward, C., Fabry, Z., and Johnson, J. A. (2010). The absence of the pro-antioxidant transcription factor Nrf2 exacerbates experimental autoimmune encephalomyelitis. Toxicol. Sci. 114, 237-246. doi: 10.1093/toxsci/kfp274

Kasai, S., Shimizu, S., Tatara, Y., Mimura, J., and Itoh, K. (2020). Regulation of Nrf2 by mitochondrial reactive oxygen species in physiology and pathology. Biomolecules 10:320. doi: 10.3390/biom 10020320
Kihara, Y., Matsushita, T., Kita, Y., Uematsu, S., Akira, S., Kira, J.-I., et al. (2009). Targeted lipidomics reveals mPGES-1-PGE2 as a therapeutic target for multiple sclerosis. Proc. Natl. Acad. Sci. U. S. A. 106, 21807-21812. doi: 10.1073/pnas. 0906891106

Kobayashi, A., Ohta, T., and Yamamoto, M. (2004). Unique function of the Nrf2Keapl pathway in the inducible expression of antioxidant and detoxifying enzymes. Meth. Enzymol. 378, 273-286. doi: 10.1016/s0076-6879(04)78 021-0

Lavrnja, I., Stojkov, D., Bjelobaba, I., Pekovic, S., Dacic, S., Nedeljkovic, N., et al. (2008). Ribavirin ameliorates experimental autoimmune encephalomyelitis in rats and modulates cytokine production. Int. Immunopharmacol. 8, 1282-1290. doi: 10.1016/j.intimp.2008.05.008

Mason, D., MacPhee, I., and Antoni, F. (1990). The role of the neuroendocrine system in determining genetic susceptibility to experimental allergic encephalomyelitis in the rat. Immunology 70, 1-5.

Melief, J., de Wit, S. J., van Eden, C. G., Teunissen, C., Hamann, J., Uitdehaag, B. M., et al. (2013). HPA axis activity in multiple sclerosis correlates with disease severity, lesion type and gene expression in normal-appearing white matter. Acta Neuropathol. 126, 237-249. doi: 10.1007/s00401-013-1140-7

Miljković, D., and Spasojević, I. (2013). Multiple sclerosis: molecular mechanisms and therapeutic opportunities. Antioxid. Redox Signal. 19, 2286-2334. doi: 10.1089/ars.2012.5068

Milosevic, A., Janjic, M. M., Lavrnja, I., Savic, D., Bozic, I. D., Tesovic, K., et al. (2020). The sex-specific patterns of changes in hypothalamic-pituitary-gonadal axis during experimental autoimmune encephalomyelitis. Brain Behav. Immun. 89, 233-244. doi: 10.1016/j.bbi.2020.06.025

Mittal, M., Siddiqui, M. R., Tran, K., Reddy, S. P., and Malik, A. B. (2014). Reactive oxygen species in inflammation and tissue injury. Antioxid. Redox Signal. 20, 1126-1167. doi: 10.1089/ars.2012.5149

Navarro-Gonzálvez, J. A., García-Benayas, C., and Arenas, J. (1998). Semiautomated measurement of nitrate in biological fluids. Clin. Chem. 44, 679-681. doi: 10.1093/clinchem/44.3.679

Prevatto, J. P., Torres, R. C., Diaz, B. L., Silva, P. M. R. E., Martins, M. A. and Carvalho, V. F. (2017). Antioxidant treatment induces hyperactivation of the HPA axis by upregulating ACTH receptor in the adrenal and downregulating glucocorticoid receptors in the pituitary. Oxid. Med. Cell. Longev. 2017:4156361.

Procaccini, C., Pucino, V., De Rosa, V., Marone, G., and Matarese, G. (2014). Neuro-endocrine networks controlling immune system in health and disease. Front. Immunol. 5:143. doi: 10.3389/fimmu.2014.00143

Rivest, S. (2010). "Chapter 4 - interactions between the immune and neuroendocrine systems," in Progress in Brain Research, Vol. 181, ed. L. Martini (Amsterdam: Elsevier), 43-53. doi: 10.1016/s0079-6123(08)81004-7

Sarraf, P., Frederich, R. C., Turner, E. M., Ma, G., Jaskowiak, N. T., Rivet, D. J. III, et al. (1997). Multiple cytokines and acute inflammation raise mouse leptin levels: potential role in inflammatory anorexia. J. Exp. Med. 185, 171-175. doi: $10.1084 /$ jem.185.1.171

Schiavone, S., Jaquet, V., Trabace, L., and Krause, K. H. (2013). Severe life stress and oxidative stress in the brain: from animal models to human pathology. Antioxid. Redox Signal. 18, 1475-1490. doi: 10.1089/ars.2012.4720

Silverman, M. N., Pearce, B. D., Biron, C. A., and Miller, A. H. (2005). Immune modulation of the hypothalamic-pituitary-adrenal (HPA) axis during viral infection. Viral Immunol. 18, 41-78. doi: 10.1089/vim.2005.18.41

Smith, S. M., and Vale, W. W. (2006). The role of the hypothalamic-pituitaryadrenal axis in neuroendocrine responses to stress. Dialogues Clin. Neurosci. 8, 383-395. doi: 10.31887/dcns.2006.8.4/ssmith

Smith, T., Schmied, M., Hewson, A. K., Lassmann, H., and Cuzner, M. L. (1996). Apoptosis of T cells and macrophages in the central nervous system of intact and adrenalectomized Lewis rats during experimental allergic encephalomyelitis. J. Autoimmun. 9, 167-174. doi: 10.1006/jaut.1996.0020

Sorrells, S. F., and Sapolsky, R. M. (2007). An inflammatory review of glucocorticoid actions in the CNS. Brain Behav. Immun. 21, 259-272. doi: 10.1016/j.bbi.2006.11.006

Spiers, J. G., Chen, H.-J. C., Sernia, C., and Lavidis, N. A. (2015). Activation of the hypothalamic-pituitary-adrenal stress axis induces cellular oxidative stress. Front. Neurosci. 8:456. doi: 10.3389/fnins.2014.00456

Spiga, F., Liu, Y., Aguilera, G., and Lightman, S. L. (2011). Temporal effect of adrenocorticotrophic hormone on adrenal glucocorticoid steroidogenesis: 
involvement of the transducer of regulated cyclic AMP-response elementbinding protein activity. J. Neuroendocrinol. 23, 136-142. doi: 10.1111/j.13652826.2010.02096.x

Stefferl, A., Linington, C., Holsboer, F., and Reul, J. M. (1999). Susceptibility and resistance to experimental allergic encephalomyelitis: relationship with hypothalamic-pituitary-adrenocortical axis responsiveness in the rat. Endocrinology 140, 4932-4938. doi: 10.1210/endo.140.11.7109

Tanaka, K., Saito, R., Sanada, K., Nishimura, H., Nishimura, K., Sonoda, S., et al. (2020). Expression of hypothalamic feeding-related peptide genes and neuroendocrine responses in an experimental allergic encephalomyelitis rat model. Peptides 129:170313. doi: 10.1016/j.peptides.2020.170313

Trifunović, S., Manojloviæ-Stojanoski, M., Ajdžanoviæ, V., Nestoroviæ, N., Ristiæ, N., Medigoviæ, I., et al. (2014). Effects of genistein on stereological and hormonal characteristics of the pituitary somatotrophs in rats. Endocrine 47, 869-877. doi: 10.1007/s12020-014-0265-3

Villacara, A., Kumami, K., Yamamoto, T., Mrsulja, B. B., and Spatz, M. (1989). Ischemic modification of cerebrocortical membranes: 5-hydroxytryptamine receptors, fluidity, and inducible in vitro lipid peroxidation. J. Neurochem. 53, 595-601. doi: 10.1111/j.1471-4159.1989.tb07375.x
Webster Marketon, J. I., and Glaser, R. (2008). Stress hormones and immune function. Cell. Immunol. 252, 16-26. doi: 10.1016/j.cellimm.2007. 09.006

Yao, C., Sakata, D., Esaki, Y., Li, Y., Matsuoka, T., Kuroiwa, K., et al. (2009). Prostaglandin E2-EP4 signaling promotes immune inflammation through Th1 cell differentiation and Th17 cell expansion. Nat. Med. 15, 633-640. doi: 10. 1038/nm.1968

Conflict of Interest: The authors declare that the research was conducted in the absence of any commercial or financial relationships that could be construed as a potential conflict of interest.

Copyright (๐ 2021 Trifunovic, Stevanovic, Milosevic, Ristic, Janjic, Bjelobaba, Savic, Bozic, Jakovljevic, Tesovic, Laketa and Lavrnja. This is an open-access article distributed under the terms of the Creative Commons Attribution License (CC BY). The use, distribution or reproduction in other forums is permitted, provided the original author(s) and the copyright owner(s) are credited and that the original publication in this journal is cited, in accordance with accepted academic practice. No use, distribution or reproduction is permitted which does not comply with these terms. 